\title{
Examination of Depressive Tendencies via Negative Automatic Thoughts in University Students
}

\author{
Sultan Okumuşoğlu ${ }^{1^{\star}}$ \\ ${ }^{1}$ European University of Lefke, Lefke, N. CYPRUS
}

Received 25 July 2017 - Revised 28 September 2017 • Accepted 10 October 2017

\begin{abstract}
Examination of depressive tendencies among university students studying in North Cyprus in terms of factors as gender, class, economic status and satisfaction level from current social connections were aimed. Automatic Thoughts Scale (ATQ) was used to measure depressive tendencies. Participants were reached according to availability principle. Participants are 171 volunteered university students whose origin country is Turkey and studying in various universities at North Cyprus ( 85 females; 87 freshmen84 senior; age range $18-30, \bar{X}$ age $=21.25, S D=2.99$ ). According to variance analysis, freshmen students differed with significantly higher mean scores regarding total ATQ scores, 'confusion and escape fantasies', 'loneliness/isolation' and 'giving up/helplessness' subscales of ATQ. Males differed with significantly higher loneliness/isolation scores than females. Statistically significant depressive tendency differences in terms of ATQ total and all subscales among different economic levels were determined. The students who 'unsatisfied' with their current social connections differed with significantly higher depressive tendencies from students who are 'satisfied'.
\end{abstract}

Keywords: depressive tendencies, economic status, negative automatic thoughts, North Cyprus, social connections, university students

\section{INTRODUCTION}

University students are people who are in a transition period from high school to university and from childhood to adulthood. This transition period brings a myriad of changes especially for students who go to universities away from their home cities, especially whose study abroad. Being away from home brings many challenges in their lives for the first time. They lose family supervision, they have to deal with everything as adults do; like constructing new social relationships, dealing with daily problems and making things happen with certain amount of finance without close supervision of parents.

In literature rapid life changes are associated with development of depression (Read et al., 2002). It is also emphasized that depression and maladjustment are risk factors regarding school dropouts (Veldman et al., 2014). Beside there is a possibility that some of the students might have financial difficulties with varying degrees and in related literature financial difficulties are also associated with depression (Ovuga, Boardman, \& Wasserman, 2006).

World Health Organization explains depression as a worldwide problem which affects millions of people (more than 300 million). Depression causes great suffering and poor functioning in many areas of life including school, family and work (World Health Organization [WHO], 2013). It is accepted as a psychological disorder which is prevalent across countries and cultures (Kessler \& Bromet, 2013). Depression is also associated with suicides and WHO (2013) reported depression as the second leading cause of deaths through suicide among people who are at 18-29 age range.

It was claimed that psychological problems like depression are prevalent among students and these problems are associated with school dropouts which deteriorates the future income prospects of the students who dropout their school (Hjorth et al., 2016). 


\section{Contribution of this paper to the literature}

- Results have implications regarding the importance of awareness about the possible psychological and economic support needs of university students studying overseas.

- Examination of depressive tendency differences of university students studying overseas in terms of some factors (as economic status, class, gender and satisfaction level from their new social connections for students who found themselves in a completely new environment) is important regarding theory of depression and has implications in terms of preventive practical applications against the depression in youth.

- $\quad$ Findings emphasize the importance of planning and conducting supportive interventions for university students, especially for freshmen.

Activation hypothesis suggests that negative cognitions in the form of automatic thoughts will be in higher frequencies among depressed individuals. According to predictions of cognitive model the existence of depressive core beliefs as "I am worthless" and as "Nobody loves me" -in other words presence of negative schemas- can be inferred through certain negative automatic thoughts which are associated with these core beliefs (Beck, 2011; Beck \& Haigh, 2014; Hollon, \& Kendall, 1980). It was claimed that through negative automatic thoughts it is possible to differentiate depressive individuals from nondepressed (Hollon \& Kendall, 1980; Hisli, 1988; Şahin \& Şahin,1992).

Therefore there are myriad of studies focusing on psychological difficulties of freshmen (e.g. Chaló, Pereira, Batista, \& Sancho, 2017; Dyson \& Renk, 2006) and adjustment levels and also stress, anxiety and depression levels of university students (e.g. Nurluöz \& Esmailzadeh, 2017; Katz \& Somers, 2017)

Under the light of the related literature, in this study examination of depressive tendencies through negative automatic thoughts among university students studying abroad in terms of some factors as gender, class and economic status and also level of satisfaction from their current social connections were aimed.

\section{METHOD}

\section{Participants}

Data collected from 171 university students (85 females and 86 males) who are from various regions of Turkey and studying in various universities in Cyprus which means they are studying abroad. Age range of participants is 18 to $30(X=21.25, S D=2.99)$. Participants were reached via snowball sampling. Snowball sampling and quato sampling were used together to create a certain amount of equivalence in gender and class. Since first year of college was associated with high levels of stress (Chaló, Pereira, Batista, \& Sancho, 2017; Dyson \& Renk, 2006) and high rate of school dropouts (Hjorth et al., 2016), freshmen especially included to the research. In order to see the differences between new beginners and fourth grades, seniors were also included. Second and thirth grades were excluded. Therefore participants were 87 freshmen and 84 senior university students. Only five scales were eliminated due to incompleted items. Ethical principles were followed and informed consent was taken from each participant. After explanations about the study, students who enrolled to participate answered the scales.

\section{Instruments}

\section{Personal information form}

Information about participants as gender, class and self-reported economic level and also self-reported level of satisfaction from their own current social connections handled through this scale. To handle self-reported economic status levels participants are asked to rate their current economic level from 1 to 5 ( $1={ }^{\prime}$ low income level', $2==^{\prime}$ middle level', 3='above middle', $4={ }^{\prime}$ high' and 5='very high').

In order to handle self-reported level of satisfaction from their social connections at their new environment they asked to rate the level of satisfaction they have from their current social connections. Self-reported level of satisfaction was rated on a 3 point likert by participants ( $1=$ Unsatisfied, $2=\mathrm{A}$ little, and $3=$ Satisfied).

\section{Automatic Thoughts Questionnaire (ATQ)}

The questionnaire which was developed by Hollon and Kendal (1980) to measure negative automatic thoughts associated with depressive tendencies was used. The scale has 30 items which rated through 5 point likert type rating. Turkish standardization was conducted by Şahin and Şahin (1992). Cronbach's Alpha and split-half 
Table 1. Results of ANOVA for ATQ and factors regarding gender $(\mathrm{N}=171)$

\begin{tabular}{ccccccc}
\hline Variable & Gender & $\mathbf{N}$ & $\overline{\mathbf{X}}$ & SD & $\mathbf{F}$ & $\mathbf{P}$ \\
\hline \multirow{2}{*}{ Lon/Isol } & Female & 85 & 9.50 & 3.09 & $4.234^{*}$ & 0.04 \\
\cline { 2 - 7 } & Male & 86 & 10.53 & 3.43 & & \\
\hline
\end{tabular}

$\mathrm{P}<0.05, \mathrm{ATQ}=$ Automatic Thoughts Questionnaire; Lon/Isol=Loneliness Isolation

Table 2. Results of ANOVA for ATQ and factors regarding class $(\mathrm{N}=171)$

\begin{tabular}{ccccccc}
\hline Variable & Class & $\mathbf{n}$ & $\overline{\mathbf{X}}$ & SD & $\mathbf{F}$ & $\mathbf{P}$ \\
\hline \multirow{2}{*}{ TotATQ } & Freshman & 87 & 81.21 & 21.34 & $5.011^{*}$ & 0.026 \\
\cline { 2 - 7 } & Senior & 84 & 73.29 & 24.84 & & \\
\hline \multirow{2}{*}{ CEF } & Freshmen & 87 & 17.04 & 4.81 & $5.344^{*}$ & 0.022 \\
\cline { 2 - 7 } & Senior & 84 & 15.25 & 5.33 & & 0.029 \\
\hline \multirow{2}{*}{ Lon/isol } & Freshmen & 87 & 10.56 & 2.96 & $4.845^{*}$ & \\
\cline { 2 - 7 } & Senior & 84 & 9.46 & 3.54 & & 0.009 \\
\hline \multirow{2}{*}{ GvupHIp } & Freshmen & 87 & 10.63 & 3.16 & $7.030^{*}$ & \\
\cline { 2 - 7 } & Senior & 84 & 9.22 & 3.75 & & \\
\hline
\end{tabular}

$\mathrm{P}<0.05$, TotATQ $=$ Total automatic thought questionnaire scores, $C E F=$ Confusion \& escape fantasies, Lon/İsol=Loneliness İsolation, GvupHIp $=$ giving up/helplessness'

reliability regarding ATQ Turkish standardized form were informed consequently as 0.93 and 0.91 (Şahin \& Şahin,1992).

It was shown that ATQ could successfully differentiate depressive individuals from nondepressed (Hollon \& Kendall, 1980). This differentiation ability between depressed-nondepressed is also informed regarding Turkish form of the scale (Hisli, 1988; Şahin \& Şahin,1992). The factor analysis of the questionnaire revealed five factors as 'negative self-concept', 'confusion and escape fantasies', 'personal maladjustment and desire for change', 'loneliness/isolation' and 'giving up/helplessness' (Şahin \& Şahin, 1992). In the presented study Cronbach's Alpha and split-half reliability of ATQ were found consequently as 0.95 and 0.90 .

\section{RESULTS}

One way analysis of variance (ANOVA) conducted to examine depressive tendency differences in terms of ATQ total and factors of ATQ in terms of gender. Results revealed statistically significant differences between male and female students only for loneliness isolation factor of ATQ $(F(1,169)=4.234, p=0.04, p<.05)$. Males differed with significantly higher ATQ loneliness/isolation mean scores $(X=10.53, S D=3.43)$ than females $(X=9.50, S D=3.09)$.

No significant gender differences were found for total ATQ scores and for other four factors of ATQ as 'negative self-concept', 'confusion and escape fantasies', 'personal maladjustment and desire for change', and 'giving up/helplessness' (See Table 1).

One way analysis of variance (ANOVA) conducted to examine depressive tendency differences regarding class revealed statistically significant differences in terms of total ATQ scores $(F(1,169)=5.011, p=0.026, p<.05)$, 'confusion and escape fantasies' $(\mathrm{F}(1,169)=5.344, \mathrm{p}=0.022, \mathrm{p}<.05)$, 'loneliness/isolation' $(\mathrm{F}(1,169)=4.845, \mathrm{p}=0.029$, $\mathrm{p}<.05)$, and 'giving up/helplessness' $(\mathrm{F}(1,169)=7.030, \mathrm{p}=0.009, \mathrm{p}<.05)$, factors of ATQ.

As can be seen from Table 2, freshmen students differed with significantly higher mean scores regarding total ATQ scores (freshmen: $X=81.21, \mathrm{SD}=21.34$; seniors: $X=73.29, \mathrm{SD}=24.84$ ), and regarding 'confusion and escape fantasies' (freshmen: $X=17.04, S D=4.81$; seniors: $X=15.25, S D=5.33$ ), 'loneliness/isolation' (freshmen: $X=10.56$, $\mathrm{SD}=2.96$; seniors: $X=9.46, \mathrm{SD}=3.54$ ), and 'giving up/helplessness' subscales (freshmen: $X=10.63, \mathrm{SD}=3.16$; seniors: $X=9.22, \mathrm{SD}=3.75$ ), of ATQ. No differences between grades were found in terms of 'negative self-concept' and "personal maladjustment desire for change' subscales (See Table 2).

One way variance analysis (ANOVA) conducted to examine depressive tendency differences regarding selfreported economic status. Despite the fact that participants are asked to rate by choosing from five economic levels, since none of them choose 'low income" level, analysis were carried out with left four level which are 'middle', 'above middle', 'high' and 'very high'.

Analysis revealed statistically significant differences in terms of total ATQ scores $(F(3,167)=12.845, p=0.000$, $\mathrm{p}<.05)$, 'negative self-concept' $(\mathrm{F}(3,167)=12.425, \mathrm{p}=0.000, \mathrm{p}<.05)$, 'confusion and escape fantasies' $(\mathrm{F}(3,167)=8.487$, $\mathrm{p}=0.000, \mathrm{p}<.05)$, 'personal maladjustment and desire for change' $(\mathrm{F}(3,167)=6.510, \mathrm{p}=0.000, \mathrm{p}<.05)$, 'loneliness/ isolation' $(\mathrm{F}(3,167)=8.173, \mathrm{p}=0.000, \mathrm{p}<.05)$, and 'giving up/helplessness' subscales of ATQ $(\mathrm{F}(3,167)=15.234$, $\mathrm{p}=0.000, \mathrm{p}<.05)$. 
Table 3. Results of ANOVA for ATQ and factors regarding self-reported economic status ( $N=171)$

\begin{tabular}{|c|c|c|c|c|c|c|}
\hline Variable & ES & $\mathbf{n}$ & $\overline{\mathbf{X}}$ & SD & $\mathbf{F}$ & $\mathbf{p}$ \\
\hline \multirow{4}{*}{ TotATQ } & Middle & 30 & 91.73 & 17.49 & $12.845^{*}$ & 0.000 \\
\hline & Above middle & 29 & 89.41 & 20.77 & & \\
\hline & High & 39 & 75.38 & 20.89 & & \\
\hline & Very high & 73 & 67.64 & 23.00 & & \\
\hline \multirow{4}{*}{ NegSC } & Middle & 30 & 30.80 & 6.26 & $12.425^{*}$ & 0.000 \\
\hline & Above middle & 29 & 29.44 & 7.06 & & \\
\hline & High & 39 & 23.38 & 8.11 & & \\
\hline & Very high & 73 & 21.69 & 9.18 & & \\
\hline \multirow{4}{*}{ CEF } & Middle & 30 & 18.56 & 3.81 & $8.487^{*}$ & 0.000 \\
\hline & Above middle & 29 & 18.24 & 5.24 & & \\
\hline & High & 39 & 16.51 & 4.94 & & \\
\hline & Very high & 73 & 14.16 & 4.97 & & \\
\hline \multirow{4}{*}{ PMDFC } & Middle & 30 & 9.4 & 2.07 & $6.510^{*}$ & 0.000 \\
\hline & Above middle & 29 & 9.10 & 2.04 & & \\
\hline & High & 39 & 7.74 & 2.29 & & \\
\hline & Very high & 73 & 7.42 & 2.80 & & \\
\hline \multirow{4}{*}{ Lon/Isol } & Middle & 30 & 11.66 & 2.72 & $8.173^{*}$ & 0.000 \\
\hline & Above middle & 29 & 11.44 & 3.37 & & \\
\hline & High & 39 & 9.84 & 2.91 & & \\
\hline & Very high & 73 & 8.87 & 3.24 & & \\
\hline \multirow{4}{*}{ GvupHlp } & Middle & 30 & 11.73 & 2.82 & $15.234^{*}$ & 0.000 \\
\hline & Above middle & 29 & 12.13 & 3.54 & & \\
\hline & High & 39 & 10.15 & 3.11 & & \\
\hline & Very high & 73 & 8.21 & 3.13 & & \\
\hline
\end{tabular}

$\mathrm{P}<0.05$, ES=Economic Status; TotATQ $=$ Total automatic thought questionaire scores; NegSC= negative self-concept'; CEF=Confusion \& escape fantasies; PMDFC=personal maladjustment and desire for change; Lon/Isol=Loneliness İsolation; GvupHlp= giving up/helplessness'

According to post hoc tests (Tukey) as can be seen from Table 3, participants who informed high and very high economic levels differed with significantly lower total ATQ scores from the participants who informed their economic levels as middle and above the middle.

Participants who reported high and very high economic levels differed with significantly lower negative selfconcept scores from the participants who informed their economic levels as middle and above the middle. Regarding confusion and escape fantasies participants with very high economic level differed with significantly lower scores from the participants whose economic levels are middle and above the middle. In terms of personal maladjustment and desire for change factor scores participants with very high economic level differed with significantly lower scores from the participants whose economic levels are middle and above the middle. Also participants with high economic level differed with significantly lower personal maladjustment and desire for change scores from the participants whose economic levels are middle.

According to post hoc tests participants who informed very high economic levels differed with significantly lower loneliness isolation scores from the participants whose economic levels are middle and above the middle.

Regarding giving up/helplessness factor scores participants with very high economic level differed with significantly lower mean scores from the participants whose economic levels are middle, above the middle and high (See Table 3).

One way ANOVA conducted to examine depressive tendency differences regarding participants' self-reported level of satisfaction from their current social connections at their current environment. Except 'personal maladjustment and desire for change' subscale of ATQ which no statistically significant differences was found $(\mathrm{F}(3,167)=1.593, \mathrm{p}=0.206, \mathrm{p}<.05)$, analysis revealed statistically significant differences for ATQ total $(\mathrm{F}(2,168)=7.169$, $\mathrm{p}=0.001, \mathrm{p}<.05)$, and other four subscales of ATQ which are negative self concept $(\mathrm{F}(3,167)=5.347, \mathrm{p}=0.006, \mathrm{p}<.05)$, confusion and escape fantasies $(\mathrm{F}(3,167)=7.118, \mathrm{p}=0.001, \mathrm{p}<.05)$, loneliness isolation $(\mathrm{F}(3,167)=7.636, \mathrm{p}=0.001, \mathrm{p}<.05)$ and 'giving up/helplessness' subscales of ATQ $(F(3,167)=9.705, \mathrm{p}=0.000, \mathrm{p}<.05)$.

As can be seen from Table 4, the students who 'unsatisfied' with their current social connections differed with significantly higher mean scores from students who are 'satisfied' and 'a little satisfied' in terms of ATQ total mean scores. Between 'satisfied' and 'a little satisfied' groups no statistically significant differences were found.

In terms of 'negative self-concept' 'unsatisfied' group differed with higher mean scores from 'satisfied' group. 
EURASIA J Math Sci and Tech Ed

Table 4. Results of ANOVA for ATQ and factors regarding self-reported satisfaction about current social connections ( $N=171)$

\begin{tabular}{|c|c|c|c|c|c|c|}
\hline Variable & SFCSC & $n$ & $\overline{\mathbf{x}}$ & SD & $\mathbf{F}$ & p \\
\hline \multirow[t]{3}{*}{ TotATQ } & Unsatisfied & 74 & 84.25 & 19.59 & $7.169^{\star}$ & 0.001 \\
\hline & A little & 60 & 74.63 & 23.82 & & \\
\hline & Satisfied & 37 & 67.83 & 25.95 & & \\
\hline \multirow[t]{3}{*}{ NegSC } & Unsatisfied & 74 & 27.24 & 7.60 & $5.347^{\star}$ & 0.006 \\
\hline & A little & 60 & 24.26 & 8.79 & & \\
\hline & Satisfied & 37 & 21.67 & 10.53 & & \\
\hline \multirow[t]{3}{*}{ CEF } & Unsatisfied & 74 & 17.78 & 4.43 & $7.118^{*}$ & 0.001 \\
\hline & A little & 60 & 15.16 & 5.25 & & \\
\hline & Satisfied & 37 & 14.54 & 5.48 & & \\
\hline \multirow[t]{3}{*}{ PMDFC } & Unsatisfied & 74 & 8.50 & 2.24 & 1.593 & 0.206 \\
\hline & A little & 60 & 7.98 & 2.85 & & \\
\hline & Satisfied & 37 & 7.62 & 2.68 & & \\
\hline \multirow[t]{3}{*}{ Lon/Isol } & Unsatisfied & 74 & 10.87 & 2.88 & $7.636^{*}$ & 0.001 \\
\hline & A little & 60 & 9.98 & 3.42 & & \\
\hline & Satisfied & 37 & 8.37 & 3.33 & & \\
\hline \multirow[t]{3}{*}{ GvupHlp } & Unsatisfied & 74 & 11.14 & 2.76 & $9.705^{*}$ & 0.000 \\
\hline & A little & 60 & 9.45 & 3.54 & & \\
\hline & Satisfied & 37 & 8.32 & 4.07 & & \\
\hline
\end{tabular}

$\mathrm{P}<0.05, \quad \mathrm{SFCSC}=$ Level of satisfaction from current social connections; TotATQ=Total automatic thought questionnaire scores; NegSC $=$ negative self-concept'; CEF=Confusion \& escape fantasies; PMDFC=personal maladjustment and desire for change; Lon/İsol=Loneliness İsolation; GvupHIp= giving up/helplessness'

In terms of 'confusion and escape fantasies', 'unsatisfied' group differed with higher mean scores from 'satisfied' and 'a little satisfied' groups.

In terms of 'loneliness/isolation' 'satisfied' group differed with lower mean scores from 'unsatisfied' and 'a little satisfied' groups.

As can be seen from Table 4, in terms of 'giving up/helplessness' subscale of ATQ, 'unsatisfied' group differed with significantly higher mean scores from students who are 'satisfied' and 'a little satisfied'. Between 'satisfied' and 'a little satisfied' groups no statistically significant differences were found (See Table 4).

Pearson correlation analysis were conducted to see relations among variables. As can be seen from Table 5, according to the results of correlation analysis 'social connection satisfaction level' correlated positively with economic status $(\mathrm{r}=.48, \mathrm{p}<.01)$ and class $(\mathrm{r}=.71, \mathrm{p}<.01)$. On the other hand 'social connection satisfaction level' correlated negatively with ATQ total and all subscales of ATQ. Economic status correlated negatively with total ATQ and all subscales of ATQ. Class correlated positively with social connection satisfaction level and negatively with ATQ total and confusion escape fantasies, loneliness isolation and giving up helplessness thoughts. As expected, positive correlations among ATQ total and subscales of ATQ were found (See Table 5).

Predictors of ATQ were analized through stepwise regression analysis. Gender, age, class and economic status variables were entered as variables. Results revealed that economic status is best predictor of depressive tendencies which explained the $18 \%$ of the variance of ATQ total. On the other hand when gender entered to the equation economic status and gender together explained the $20.4 \%$ of the variance of total depressive tendencies (see Table $6)$. 
Table 5. Results of Correlation Analysis

\begin{tabular}{|c|c|c|c|c|c|c|c|c|c|c|c|}
\hline Variables & age & ES & Class & gender & SC & TATQ & NegSC & CEF & PMDF & Lonl & GvH \\
\hline age & 1 & & & & & & & & & & \\
\hline ES & .036 & 1 & & & & & & & & & \\
\hline class & .049 & $.411^{* *}$ & 1 & & & & & & & & \\
\hline gender & .113 & .145 & -.053 & 1 & & & & & & & \\
\hline SC & .075 & $.488^{* \star}$ & $.711^{* *}$ & -.066 & 1 & & & & & & \\
\hline TATQ & .001 & $-.424^{* *}$ & $-.170^{*}$ & .091 & $-.279^{\star *}$ & 1 & & & & & \\
\hline NegSC & .038 & $-.415^{* *}$ & -.136 & .086 & $-.244^{* *}$ & $.955^{* *}$ & 1 & & & & \\
\hline CEF & -.076 & $-.352^{* *}$ & $-.175^{*}$ & .057 & $-.264^{\star \star}$ & $.919^{* *}$ & $.812^{* *}$ & 1 & & & \\
\hline PMDF & .002 & $-.313^{* *}$ & -.081 & -.046 & -.136 & $.779^{* *}$ & $.687^{\star *}$ & $.717^{* *}$ & 1 & & \\
\hline Lonl & -.004 & $-.350^{\star *}$ & $-.167^{*}$ & $.156^{*}$ & $-.284^{\star \star}$ & $.853^{\star \star}$ & $.778^{\star \star}$ & $.738^{* *}$ & $.644^{\star \star}$ & 1 & \\
\hline $\mathrm{GvH}$ & .003 & $-.435^{* *}$ & $-.200^{* *}$ & .030 & $-.320^{\star *}$ & $.872^{* \star}$ & $.783^{* *}$ & $.829^{* *}$ & $.585^{\star \star}$ & $.726^{* *}$ & 1 \\
\hline
\end{tabular}

**. Correlation is significant at the 0.01 level. ${ }^{*}$. Correlation is significant at the 0.05 level.

ES=Economic Status; SC=Social connection; TATQ=Total automatic thought questionaire scores; NegSC=negative self-concept;

$\mathrm{CEF}=$ Confusion \& escape fantasies; $\mathrm{PMDF}=$ personal maladjustment and desire for change; LonI =Loneliness İsolation;

$\mathrm{GvH}=$ giving up/helplessness.

Table 6. Predictors of ATQ according to stepwise regression analysis

\begin{tabular}{cccccccc}
\hline Predictors & $\mathbf{R}$ & $\mathbf{R}^{\mathbf{2}}$ & $\mathbf{B}$ & Beta & StdError & $\mathbf{F}$ & $\mathbf{P}$ \\
\hline ES & .424 & .180 & -8.715 & -.424 & 1.431 & $37.073^{\star}$ & 0.000 \\
\hline Gender & .451 & .204 & 7.246 & .155 & 3.247 & $21.462^{\star}$ & 0.000 \\
\hline
\end{tabular}

${ }^{*} \mathrm{p}<.05 ;$ ATQ:Automatic thoughts questionaire; ES:Economic status

\section{DISCUSSION}

In literature first year of college was associated with high levels of stress since it is an adaptation period to new conditions (Chaló, Pereira, Batista, \& Sancho, 2017; Dyson \& Renk, 2006) and also associated with high rate of school dropouts (Hjorth et al., 2016), freshmen period seems as an especially important period. Therefore freshmen and seniors were included as participants of the current study. Examination of depressive tendencies via negative automatic thoughts among university students studying overseas in terms of some factors as gender, class and economic status and also regarding the level of satisfaction from their current social connections were aimed.

As can be seen from the results of the current study, no statistically significant differences was found between females and males in terms of ATQ total and subscales of ATQ as 'negative self-concept', 'confusion and escape fantasies', 'personal maladjustment and desire for change', and 'giving up/helplessness'.

Some other studies in literature informed no differences according to gender in terms of frequency of negative automatic thoughts (Odac1, 2007; Şirin \& Izgar, 2013) and class (Şirin \& Izgar, 2013).

On the other hand in the current study males differed only with significantly higher loneliness/isolation subscale mean scores than females. The participants of the present study are differed as studying abroad. Difference in terms of loneliness/isolation thoughts which needs further clarification by future research could be related with difficulties experienced by male students while constructing new social connections away from home perhaps since female students generally are having some support body while initiating their new life at abroad.

Şirin \& Izgar (2013) informed no differences in terms of frequency of negative automatic thoughts regarding class. In the presented study no differences between grades were found in terms of frequency of negative automatic thoughts which are 'negative self-concept' and 'personal maladjustment desire for change' subscales. Despite the fact that no differences between grades were found in terms of 'negative self-concept' and 'personal maladjustment desire for change' subscales, participants from different grades differed significantly in terms of total ATQ and some subscales of ATQ. Freshmen students differed with significantly higher mean scores regarding total ATQ scores, 'confusion and escape fantasies', 'loneliness/isolation' and 'giving up/helplessness' subscales of ATQ. These findings can be accepted as parallel with the results of the study which informed a relation between having difficulties in terms of adapting to a new environment and frequency of negative automatic thoughts (Hisli, 1990).

Statistically significant differences among informed different economic levels were found in terms of total ATQ scores, 'negative self-concept', 'confusion and escape fantasies', 'personal maladjustment and desire for change', 'loneliness/isolation' and 'giving up/helplessness' subscales of ATQ. Participants who informed high and very 
high economic levels differed with significantly lower total ATQ scores from the participants who informed their economic levels as middle and above the middle. Results also revealed that economic status is the best predictor of depressive tendencies which explained the $18 \%$ of the variance of ATQ total.

Parallel with the findings of the current study, in literature economic difficulties were associated with psychological distress (Brown, Richman, \& Rospenda, 2017). As can be seen from results of current study, participants who reported high and very high economic levels also differed with significantly lower 'negative selfconcept' scores from the participants who informed their economic levels as middle and above the middle. Participants with very high economic level differed with significantly lower scores from the participants whose economic levels are informed as middle and above the middle. On the other hand, participants with high economic level differed with significantly lower personal maladjustment and desire for change scores from the participants whose economic levels are middle. Also participants which informed their economic level as very high, differed with significantly lower scores from the participants who reported their economic levels as middle and above the middle.

In terms of loneliness isolation subscale of ATQ participants who reported their economic status as very high differed with significantly lower scores from the participants whose economic levels are middle and above the middle.

In terms of giving up/helplessness subscale scores, participants with very high economic level differed with significantly lower mean scores from the participants whose economic levels are middle, above the middle and high.

In literature economic level is informed as one of the factors which affects dropouts (Hjorth et al., 2016; RowanKenyon, 2007; Ruban, Petersen, \& Møller-Madsen, 2013) which is supported with the findings of the presented study.

The students who 'unsatisfied' with their current social connections differed with significantly higher means from students who are 'satisfied' and 'a little satisfied' in terms of ATQ total scores and 'confusion and escape fantasies' and 'giving up/helplessness' subscale scores. In terms of 'loneliness/isolation', 'satisfied' group differed with lower mean scores from 'unsatisfied' and 'a little satisfied' groups. In terms of 'negative self-concept' subscale of ATQ, 'unsatisfied' group differed with higher mean scores from 'satisfied' group. Between 'satisfied' and 'a little satisfied' groups no statistically significant differences were found regarding 'giving up/helplessness' subscale scores. Between 'satisfied' and 'a little satisfied' groups no statistically significant differences were found in terms of ATQ total scores. It can be said that even a little level of satisfaction from new social connections in a new environment might be protective regarding depressive tendencies of university students.

As can be seen from results, in the presented study significant negative automatic thought differences were found among groups which informed different levels of satisfaction from their current social connections in their new environment.

According to the belongingness hypothesis every individual has a basic psychological need regarding inquiry of close social relationships which are rewarding and stable (Baumeister \& Leary, 1995). In literature perception of loneliness and attentional biases regarding negative social stimuli are associated (Cacioppo, Balogh \& Cacioppo, 2015). It was suggested that absence of preexisting social bonds creates a kind of vulnerability in which individual became vigilant for possible threads in their new environment (Cacioppo \& Hawkley, 2009). As a result this may create a vicious cycle in terms of loneliness, negative maladaptive cognitions and behaviors which generally associated with depression. Pearson correlation results which revealed social connection satisfaction level correlated negatively with ATQ total and all subscales of ATQ and correlated positively with economic status and class are parallel with the mentioned claims.

As a conclusion it can be said that young individuals who are studying overseas and lose their preexisting social connections and couldn't have new satisfying social connections are having more frequent negative automatic thoughts, and more depressive tendencies. When it is thought that lack of satisfactory social connections, psychological problems like depression or depressive tendencies, and economic problems are increasing dropout risks (Veldman et al., 2014) the importance of planning and conducting supportive interventions (in terms of economic and psychological factors) targeting university students, especially freshmen became clear.

\section{REFERENCES}

Baumeister, R. F., \& Leary, M. R. (1995). The need to belong: Desire for interpersonal attachments as a fundamental human motivation. Psychological Bulletin, 117(3), 497-529.

Beck, A. T., \& Haigh, E. A. (2014). Advances in Cognitive Theory and Therapy: The Generic Cognitive Model. Annual Review of Clinical Psychology, 10, 1-24. doi: 10.1146/annurev-clinpsy-032813-153734 PMID: 24387236

Beck, J.S. (2011). Cognitive Therapy: Basics and beyond. 2. Baskı. New York: The Guilford Press. 
Brown, R. L., Richman, J. A., \& Rospenda, K. M. (2017) Economic stressors and psychological distress: exploring age cohort variation in the wake of the great recession. Stress Health, 33, 267-277. doi:10.1002/smi.2705

Cacioppo, J. T., \& Hawkley, L. C. (2009). Perceived social isolation and cognition. Trends in Sciences, 13(10), 447-454.

Cacioppo, S., Balogh, S., \& Cacioppo, J. T. (2015). Implicit attention to negative social, in contrast to nonsocial, words in the stroop task differs between individuals high and low in loneliness: Evidence from event related brain microstates. Cortex, 70, 213-233.

Chaló, P., Pereira, A., Batista, P., \& Sancho, L. (2017). Brief biofeedback intervention on anxious freshman university students. Applied Psychophysiology and Biofeedback, 42(3), 163-168. doi:10.1007/s10484-017-9361-5

Dyson, R. \& Renk, K. (2006). Freshmen adaptation to university life: Depressive symptoms, stress, and coping. International Journal of Clinical Psychology, 62, 1231-1244. doi:10.1002/jclp.20295

Hisli, N. (1988). Beck Depresyon Envanteri'nin üniversite öğrencileri için geçerliği güvenirliği (reliability and validity of the BDI with a group of university students). Psikoloji Dergisi, 7, 3-13.

Hisli, N. (1990). Almanya'dan dönüş yapan öğrencilerden uyum yapan ve yapmayanların fonksiyonel olmayan tutumlar, olumsuz otomatik düşünceler ve problem çözme yeterliliği konusunda kendilerini algılayış açısından farklılıkları. V. Ulusal Psikoloji Kongresi Psikoloji Seminer Dergisi Özel Sayısı (8. Sayı), 711-721.

Hjorth,C. F., Bilgrav, L., Frandsen, L. S., Overgaard, C., Torp-Pedersen, C., Nielsen,B., \& Bøggild, H. (2016). Mental health and school dropout across educational levels and genders: A 4.8-year follow-up study. BMC Public Health, 16, 976. doi:10.1186/s12889-016-3622-8

Hollon, S. D., \& Kendall, P. C. (1980). Cognitive self-statements in depression: Development of an automatic thoughts questionnaire. Cognitive Therapy and Research, 4, 383-395.

Katz, S., \& Somers, C. L. (2017). Individual and environmental predictors of college adjustment: Prevention and intervention. Current Psychology, 36(1), 56-65. doi:10.1007/s12144-015-9384-0

Kessler, R. C., \& Bromet, E. J. (2013). The epidemiology of depression across cultures. Annual Reviews of Public Health, 34, 119-138.

Nurluöz, Ö., \& Esmailzadeh, S. (2017). Evaluating entrepreneurial characteristics and states of despair of nursing department students. EURASIA Journal of Mathematics, Science, Technology and Education, 13(8), 4885-4896. doi:10.12973/eurasia. 2017.00971a

Odac1, H. (2007). Submissive behaviors and automatic negative thoughts among adolescent boys and girls: A study with a Turkish sample. Social Behavior and Personality, 35(8), 1021-1026.

Ovuga, E., Boardman, J., \& Wasserman, D. (2006). Undergraduate student mental health at Makerere University, Uganda. World Psychiatry, 5(1), 51-52.

Read, J. P., Wood, M. D., Davidoff, O. J., McLacken, J., \& Campbell, J. F. (2002). Making the transition from high school to college: The role of alcohol-related social influence factors in students' drinking. Substance Abuse, 23(1), 53-65.

Rowan-Kenyon, H. T. (2007). Predictors of delayed college enrollment and the impact of socioeconomic status. Journal of Higher Education, 78, 188-214. doi: 10.1353/jhe.2007.0012

Ruban, P. U., Petersen, M. G., \& Møller-Madsen, B. (2013). More than half of the medical students who apply for a dispensation drop out and need focused counselling. Danish Medical Journal, 60, 12-12.

Şahin, N. H., \& Şahin, N. (1992). Reliability and validity of the Turkish version of the automatic thoughts questionnaire. Journal of Clinical Psychology, 48, 334-340.

Şirin, H., \& Izgar, H. (2013). Relationship between undergraduates' communication skills and their negative automatic thoughts. Elementary Education Online, 12(1), 254-266. Retrieved on 8th September 2017 from http://ilkogretim-online.org.tr

Veldman, K., Bültmann, U., Stewart, R. E., Ormel, J., Verhulst, F. C., \& Reijneveld, S. A. (2014). Mental health problems and educational attainment in adolescence: 9-year follow-up of the TRAILS study. PLoS One. 9(12), e115070.

World Health Organization [WHO]. (2013). Depression. Retrieved on 4 th September 2017 from http://www.who.int/mediacentre/factsheets/fs369/en/

\section{http://www.ejmste.com}

